\title{
Study on the influencing factors and improving countermeasures of regional financial service function in Hunan Province --Take corporate loans as an example
}

\author{
ZHIYING LIU ( 522509562@QQ.COM ) \\ Hunan Institute of Technology \\ Yixian Wen \\ Hunan Institute of Technology
}

\section{Research}

Keywords: Regional finance, Corporate credit, Influence factor

Posted Date: March 7th, 2022

DOI: https://doi.org/10.21203/rs.3.rs-1096548/v1

License: (c) (1) This work is licensed under a Creative Commons Attribution 4.0 International License. Read Full License 


\title{
Study on the influencing factors and improving countermeasures of regional financial service function in Hunan Province ------Take corporate loans as an example
}

\author{
Wen-Yixian, Liu-Zhiying (522509562@qq.com) \\ Business school, Hunan institute of technology
}

\begin{abstract}
The demand for financial services has been increasing with China rapid economic development in recent years. Among diverse financial services, credit is the financial service which has linked closely with daily economic activities of individuals and nonfinancial firms. In fact, in the domestic financial system, indirect financing is the leading way, the change in the total amount of credit is of great significance to both the microeconomic and the macroeconomic. This paper focuses on the regional financial services within Hunan Province, using the volume of credit delivery to non-financial firms and government institutions in Hunan as a start point, and selects the nonfinancial firms in Hunan Province from 2016 to 2020 as the research object, and analyses the influencing factors for the amount of non-financial corporate borrowing under the function of regional financial services in Hunan. The empirical results show that the amount of loans from non-financial enterprises are positively correlated with the deposits of non-financial enterprises and residents and government organizations and are negatively correlated with the reduction rate of loss-making enterprises and CPI. Finally, according to the results, this paper concluded countermeasures for Hunan Province to effectively improve the amount of credit and promote economic development.

Key Words: Regional finance, Corporate credit, Influence factor

Fund Project: Education Department of Hunan Province "Research on new agricultural development model under the combination of network traffic and tourism culture" (20C0580); Project of Hunan social science achievement evaluation committee "Research on the coupling relationship between regional financial services and economic development in the construction of innovative Hunan" (XSP21YBC454)
\end{abstract}




\section{Introduction}

Finance is the core competitiveness of the state, and the function of financial services is essential to the development of the real economy. Bank credit is still the most dominant of the regional financial service function in Hunan Province. The volume of loans from non-financial firms has increased rapidly in the past five years. From January 2016 to December 2020, the amount of loan in Hunan Province increased by $49.37 \%$, while loans from non-financial enterprises and institutions increased by 45.1\%. Many researches demonstrated a robust positive correlation between bank credit and economic growth in the east-central region of China. So, for the analysis of factors that affect the volume of bank credit is of strong practical significance to regional economic development (Zeng 2010).

This paper mainly empirically analyses the impact of factors such as resident deposits, resident loans, deposits of non-financial enterprises, and loss-making enterprise rate on the amount of loans obtained by enterprises, and then proposes corresponding countermeasures and recommendations.

Improving the function of regional financial services and creating a better business operating environment has always been the direction of China. Scholars have also conducted massive studies on factors affecting the function of financial services.

The first is the aggregate economy. Most findings show a strong positive relationship between bank credit and economic growth. From a regional perspective, the credit of China's financial institutions plays a significant role in promoting the economic growth of the eastern and central regions of China, but it slightly impacts the economic growth of the western regions (Chen 2021). The empirical results of Guangdong province suggest that, under the condition that market price and interest rate levels remain the same, each $1 \%$ increase in the total regional economy outputs will drive a $0.95 \%$ increase in loan size (Zeng 2010). Bo's research on Hengyang, Hunan Province also found that the size of credit increased in recent years as the total economy rose (Zhang 2010).

The second is the rate and price level. Under the condition that the economic aggregate and interest rate remain unchanged, every $1 \%$ increase in the ratio of overall price expectation (CPI / MP) will drive the growth of the loan scale by $0.72 \%$. Interest 
rate adjustment is negatively related to loan size, but compared with other variables, interest rate has a relatively weak effect on the loan size in Guangdong (Zeng 2010).

Thirdly, the impact of industrial structure on the volume of credit. Zhang Ge found that the proportion of the primary industry was large, which restricted the improvement of Henan's loan absorption capacity. Although the proportion of the secondary industry in Henan Province has been increasing in recent years, the gap between the total industrial volume of Henan Province and advanced provinces is still large. In addition, the small scale of enterprises restricts the loan capacity. Chen (2021) also found that in Hengyang, with the continuous improvement of the tertiary industry, the amount of credit is increasing.

In addition to the above factors, corporate bonds, stock markets, and other direct financing methods will also divert part of the credit demand, thus having an impact on the growth of regional bank credit. But compared with indirect financing, the scale of direct financing mentioned above is still limited. In qualitative studies, the orientation of macro policy, regulatory policy, and fiscal policy will have complex impacts on the scale of credit. Considering their influence will still be ultimately reflected in such factors as the total amount of economy, interest rate, and price, the above factors will not be considered in this study further (Zhao 2018, Li 2016).

Based on the research of the former, this paper makes some innovation and refinement in selecting influencing factors and tries to select the influencing factors with more research value according to the characteristics of regional finance in Hunan Province. Firstly, the deposits and loans of non-financial enterprises and residents are selected instead of the total economic outputs. Because the economic aggregate index is affected by many other factors, and the deposits and loans of non-financial enterprises and residents have a more direct impact on the amount of enterprise loans. Then the index of loss-making enterprise reduction rate is added. Since Small and medium enterprises dominate Hunan Province, banks will pay more attention to the internal

Author:Wen-Yixian (1986- ), female, native place: Hunan. Associate professor, master of management, graduate school: Changsha University of Science \& Technology. Research expertise: Regional Economic.E-mail: 276171532@qq.com

Liu-Zhiying (1996-) female, native place: Hunan. lecturer, master of Finance, graduate school: University of Durham. Research expertise: Regional Economic. E-mail: 522509562@qq.com. 
situation of enterprises when granting credit; therefore, the overall amount of credit will be significantly affected by this index. Finally, the consumer price index CPI is retained.

The structure of the following parts of the article is arranged as follows: the first part puts forward the research scheme, tests the impact of influencing factors on enterprise loans through econometric models, verifies assumptions, and draws the main conclusions; The second part puts forward improvement countermeasures according to the model results and combined with the development trend of the industry.

\section{Research Program}

\subsection{Research Hypotheses}

With the development of Finance market, the channels of enterprise financing are gradually diversified. However, for those banks or other financing platforms, who only play an intermediary role in financing enterprises, gathering funds from multiple and scattered sources, then lending them. Therefore, it can be assumed that the total amount of deposit is one of the essential factors determining the amount of lending. In addition, the deposit reserve ratio announced by the central bank also indirectly affects the amount of loans. Based on this, this paper considered the deposits of non-financial enterprises, resident deposits and deposit reserve ratio as variables which affect the volume of non-financial enterprises and government institutions loan.

Hypothesis 1a: There is a positive correlation between the total amount of deposits of non-financial enterprises (and residents) and the loan amount of nonfinancial enterprises and government organizations.

Hypothesis 1b: The deposit reserve ratio has a negative correlation with the loan volume of non-financial enterprises and government organizations.

The change of resident loans is not only related to the level of economic development but also related to the level of consumption. From the analysis of the total amount of loans in Hunan Province, the increase of individual loans to residents will have impact to the amount of loans to non-financial enterprises. With the increase of personal loans, the market liquidity will increase accordingly, which promotes consumption to a certain extent and benefits the development of relevant enterprises. Based on this, this paper analyses the impact of the change range of resident loans on the actual loan amount of non-financial enterprises. 
Hypothesis 2: There is a positive correlation between resident loans and loans to non-financial enterprises and government organizations.

From the macroeconomic perspective, there is an implicit relationship between the overall enterprise loss rate in a region and the amount of enterprise loans. Because the banks would use this as an important index to measure the local companies' solvency. The reduction enterprise loss rate does not take a single enterprise as the research subject instead of revealing the development trend of industry operation from the whole industry. Therefore, it is not only related to the internal factors of the enterprise but also closely related to the macro environment. Based on this, this paper considers the change of reduction rate of loss-making enterprises as an independent variable.

Hypothesis 3: The reduction rate of loss-making enterprises has a negative correlation with the loan amount of non-financial enterprises and government institutions.

The consumer price index (CPI) reflects the inflation rate of money, which have great impact on the loan volume. The interest rate and price level affect the supply and demand of money and directly affects the total amount of loans in the region. When the money supply remains unchanged, when the price level rises, the market interest rate rises, and the cost of loan for non-financial enterprises rises, which increases the loan volume.

Another index that connects to the amount of loan is SHIBOR (Shanghai Interbank Offered Rate). SHIBOR is the arithmetic average interest rate independently quoted by commercial banks with high credit rating and determined through calculation. When SHIBOR rise, the weighted average interest rate of loans from non-financial enterprises and government institutions will rise, which will affect the loan volume of non-financial enterprises and government institutions to a certain extent. Zhang and Zhao (2018) believe that market benchmark position of SHIBOR is being strengthened. It not only has an impact on the interest rate of the traditional financial market, but also has a forward-looking guiding role on the interest rate of the new Internet financial market. Based on this, this paper considers the impact of CPI and SHIBOR interest rate on the loan volume of non-financial enterprises and government institutions and puts forward the following assumptions: ${ }^{[3]}$ 
Hypothesis 4a: CPI has a negative correlation with the loan volume of nonfinancial enterprises and government institutions

\section{Hypothesis 4b: Shanghai interbank offered rate SHIBOR has a negative correlation with the loan volume of non-financial enterprises and government institutions.}

\subsection{Data source and description}

This paper used the amount of loan of non-financial enterprises and government institutions in Hunan Province as the dependent variable instead of the loan amount of non-financial enterprises as the majority of papers. And, the amount of non-financial enterprises' deposits and resident' deposits, resident loans, the reduction rate of lossmaking enterprises (compared with the same period of last year), CPI, 1-month interest rate of SHIBOR and deposit reserve ratio as independent variables. They are shown in Table 1:

Table 1 Selection of variables

\begin{tabular}{cc}
\hline Variable's Code & Variable's Name \\
\hline Y & The amount of loan of non-financial enterprises and government institutions \\
X1 & Deposits of non-financial enterprise \\
X2 & Resident deposit \\
X3 & Resident loan \\
X4 & Reduction of enterprises loss rate \\
X5 & CPI \\
X6 & SHIBOR \\
X7 & Deposit reserve ratio
\end{tabular}

Among them, the data of variable Y (the loan volume of non-financial enterprises and government organizations), X1 (deposits of non-financial enterprises), X2 (resident deposits), and X3 (resident loans in Hunan Province) were derived from People's Bank of (China Changsha branch) of Hunan Province. The reduction of enterprises loss rate (compared with the same period of last year) and CPI data were derived from the regional financial data of Hunan Province published by the National Bureau of statistics; The data of deposit reserve ratio comes from the National Bureau of statistics. SHIBOR is Shanghai interbank offered data. This paper selected 1-month SHIBOR interest rate 
particularly, because the 1-month SHIBOR interest rate can reflect the market better, it was published officially in first trading day of each month.

This paper selects the data from 2016 to 2020, which is the 13th five-year plan construction period in China. During this time, China went through a rapidly development and made lots of remarkable achievement in finance. Therefore, the analysis of the development and changes of enterprise loans in Hunan Province during the 13th five-year plan construction period has reference significance for the changes of enterprise loans under the 14th five-year Plan period.

\section{Measurement test on Influencing Factors of enterprise loan}

\subsection{OLS regression model}

Taking the loan volume of non-financial enterprises and government institutions as the dependent variable and the variables such as non-financial enterprise deposits and resident deposits as the independent variable, we test the results with the OLS estimation method. The data are shown in Table 2:

Table 2 OLS estimation results

\begin{tabular}{ccccc}
\hline Variables & Coefficient & Standard Deviation & T-statistic & P-value \\
\hline C & -13063004 & 23487866 & -0.556160 & 0.5807 \\
X1 & 0.145262 & 0.087544 & 1.659292 & 0.1037 \\
X2 & 0.280110 & 0.074360 & 3.766964 & 0.0005 \\
X3 & 1.008559 & 0.089664 & 11.24820 & 0.0000 \\
X4 & -31795560 & 8357979. & -3.804216 & 0.0004 \\
X5 & $-1.01 \mathrm{E}+08$ & 46336605 & -2.169297 & 0.0352 \\
X6 & $-2.96 \mathrm{E}+08$ & 91719673 & -3.225259 & 0.0023 \\
X7 & $2.57 \mathrm{E}+08$ & $1.15 \mathrm{E}+08$ & 2.229986 & 0.0306 \\
\hline
\end{tabular}

$\mathrm{R}^{\wedge} 2=0.996570$, F-statistic $=1950.944, \mathrm{DW}=0.861307$

It can be seen from the results in Table 2 that $\mathrm{X} 1$ is not significant. $\mathrm{X} 7$ is positively correlated with $\mathrm{Y}$, which is inconsistent with the hypothesis. Therefore, we then analysed whether there is multicollinearity between variables, resulting in insignificant variables and wrong sign of regression coefficient. The simple correlation coefficient matrix is shown in Table 3:

Table 3 simple correlation coefficient matrix

\begin{tabular}{lllllll}
$\mathrm{X} 1$ & $\mathrm{X} 2$ & $\mathrm{X} 3$ & $\mathrm{X} 4$ & $\mathrm{X} 5$ & $\mathrm{X} 6$ & $\mathrm{X} 7$ \\
\hline
\end{tabular}




\begin{tabular}{lllllllll}
\hline X1 & 1.000000 & 0.598644 & 0.576632 & -0.315461 & -0.072755 & 0.096124 & -0.371693 \\
X2 & 0.598644 & 1.000000 & 0.986574 & -0.858483 & 0.242115 & -0.516892 & -0.937506 \\
X3 & 0.576632 & 0.986574 & 1.000000 & -0.843264 & 0.238593 & -0.550851 & -0.953374 \\
X4 & -0.315461 & -0.858483 & -0.843264 & 1.000000 & -0.427604 & 0.658153 & 0.860674 \\
X5 & -0.072755 & 0.242115 & 0.238593 & -0.427604 & 1.000000 & -0.338192 & -0.359134 \\
X6 & 0.096124 & -0.516892 & -0.550851 & 0.658153 & -0.338192 & 1.000000 & 0.699289 \\
X7 & -0.371693 & -0.937506 & -0.953374 & 0.860674 & -0.359134 & 0.699289 & 1.000000 \\
\hline
\end{tabular}

It can be seen from table 3 that variable X7 is highly correlated with variables X2, $\mathrm{X} 3$, and $\mathrm{x} 4$, and it can be considered that there is serious multicollinearity between variables. Therefore, although $\mathrm{X} 7$, the deposit reserve ratio, is theoretically negatively related to the amount of loans, the currency available to banks for loans is relatively reduced with the increase of the deposit reserve ratio. Based on this, after removing the $\mathrm{X} 7$ deposit reserve ratio variable, the OLS estimation is carried out again to obtain Table 4:

Table 4 OLS estimation results

\begin{tabular}{ccccc}
\hline Variables & Coefficient & Standard Deviation & T-statistic & P-value \\
\hline C & 34899412 & 9821496. & 3.553370 & 0.0009 \\
X1 & 0.258637 & 0.074159 & 3.487598 & 0.0011 \\
X2 & 0.231607 & 0.073992 & 3.130179 & 0.0030 \\
X3 & 0.897933 & 0.077720 & 11.55346 & 0.0000 \\
X4 & -37232124 & 8318782. & -4.475670 & 0.0000 \\
X5 & $-1.46 \mathrm{E}+08$ & 43406443 & -3.352159 & 0.0016 \\
X6 & $-1.88 \mathrm{E}+08$ & 81162982 & -2.318915 & 0.0247 \\
\hline
\end{tabular}

$\mathrm{R}^{\wedge} 2=0.996207, \mathrm{~F}$-statistic $=2101.349, \mathrm{DW}$ is 0.702967

Under the significance level $\alpha=0.01$, the original hypothesis $\mathrm{H} 0$ should be rejected, because $\mathrm{F}=2101.349>6.88(\mathrm{~F}(6,53)=6.88)$, which indicates that the regression equation is significant. In addition, at the $5 \%$ significance level, all P-values in Table 4 are less than 0.05 . It could be concluded that X1, X2, X3, X4, X5, and X6 variables were significant, which indicated that the regression between the selected explanatory variable and the explained variable is meaningful. Among them, $\mathrm{Y}$ have a positive correlation with $\mathrm{X} 1, \mathrm{X} 2$, and $\mathrm{X} 3$, but a negative correlation with $\mathrm{X} 4, \mathrm{X} 5$, and $\mathrm{X} 6$. Based on this, the relationship between variables had analysed, as shown in Table 5:

Table 5 simple correlation coefficient matrix

\begin{tabular}{ccccccc}
\hline & X1 & X2 & X3 & X4 & X5 & X6 \\
\hline X1 & 1.000000 & 0.598644 & 0.576632 & -0.315461 & -0.072755 & 0.096124
\end{tabular}




\begin{tabular}{lcccccc} 
X2 & 0.598644 & 1.000000 & 0.986574 & -0.858483 & 0.242115 & -0.516892 \\
X3 & 0.576632 & 0.986574 & 1.000000 & -0.843264 & 0.238593 & -0.550851 \\
X4 & -0.315461 & -0.858483 & -0.843264 & 1.000000 & -0.427604 & 0.658153 \\
X5 & -0.072755 & 0.242115 & 0.238593 & -0.427604 & 1.000000 & -0.338192 \\
X6 & 0.096124 & -0.516892 & -0.550851 & 0.658153 & -0.338192 & 1.000000 \\
\hline
\end{tabular}

Table 5 showed that X4 has a high correlation with X2 and X3. In Table 4 of the estimation results, the regression coefficients of explanatory variables $\mathrm{X} 2$ and $\mathrm{X} 3$ showed significant. In order to make data more stable and weaken multicollinearity and heteroscedasticity, we took the logarithm of Y, X1, X2, and X3. It could be seen from table 6 that after taking the logarithm of relevant variables, the variables were significant. The results are shown in Table 6:

Table 6 OLS estimator results after logarithm

\begin{tabular}{ccccc}
\hline Variables & Coefficient & Standard Deviation & T-statistic & P-value \\
\hline C & 3.074872 & 1.065669 & 2.885392 & 0.0058 \\
LNX1 & 0.097607 & 0.044654 & 2.185853 & 0.0337 \\
LNX2 & 0.318736 & 0.087979 & 3.622880 & 0.0007 \\
LNX3 & 0.441374 & 0.044869 & 9.836901 & 0.0000 \\
X4 & -0.159535 & 0.037779 & -4.222868 & 0.0001 \\
X5 & -0.622989 & 0.205607 & -3.029998 & 0.0039 \\
X6 & -0.810055 & 0.377888 & -2.143636 & 0.0372 \\
\hline
\end{tabular}

$\mathrm{R}^{\wedge} 2=0.995329$, the estimated value of $\mathrm{F}$ is 1704.756

\subsection{Unit root test}

The unit root test of stationarity is a special method to test whether there are some statistical characteristics in time series. There are many methods to test unit root, including ADF test, PP test, DF test, KPSS test and NP test. Since the ADF test is the most popular way, this paper would test by this one. 


\section{Graph 7 Time series of loans obtained by non-financial enterprises and government institutions.}

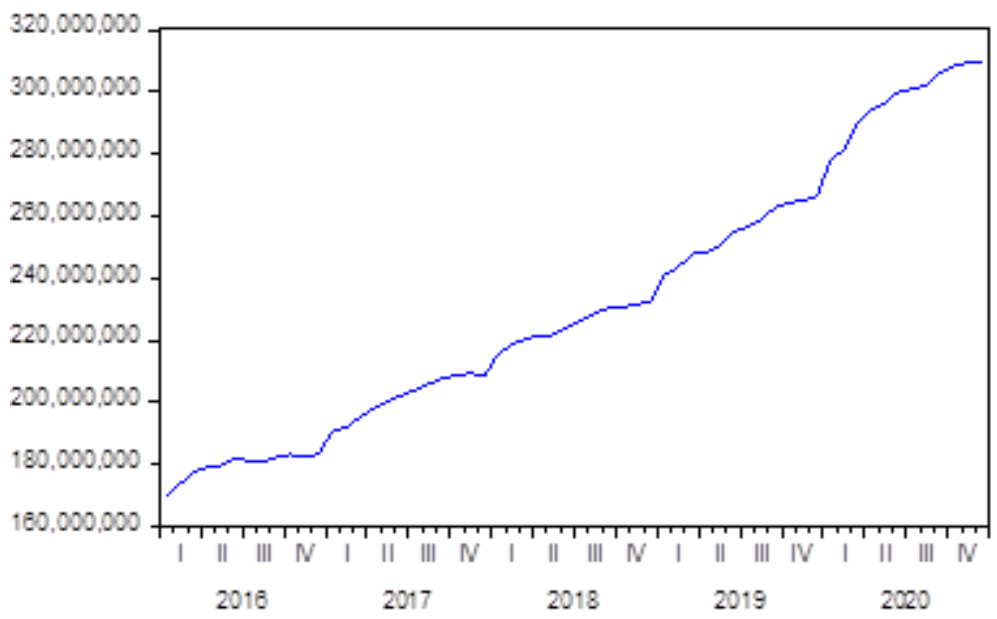

It can be found from Table 7 that the loan acquisition of non-financial enterprises and government institutions shows a fluctuating upward trend.

Table 8 stationary test results of variables

\begin{tabular}{cccccc}
\hline Variables & ADF & \multicolumn{3}{c}{ Critical value } & Stationarity \\
\hline LnY & 0.022036 & -3.546099 & -2.91173 & -2.593551 & not stationary \\
D(LnY) & -7.360552 & -3.548208 & -2.912631 & -2.594027 & stationary \\
LnX1 & -2.570602 & -3.546099 & -2.91173 & -2.593551 & Not stationary \\
D(LnX1) & -10.64678 & -3.548208 & -2.912631 & -2.594027 & stationary \\
LnX2 & -1.072335 & -3.546099 & -2.91173 & -2.593551 & Not stationary \\
D(LnX2) & -7.307594 & -3.57131 & -2.922449 & -2.599224 & stationary \\
LnX3 & -0.572881 & -3.548208 & -2.912631 & -2.594027 & Not stationary \\
D(LnX3) & -14.47459 & -3.548208 & -2.912631 & -2.594027 & stationary \\
X4 & -2.443281 & -3.568308 & -2.921175 & -2.598551 & Not stationary \\
D(X4) & -7.397832 & -3.584743 & -2.928142 & -2.602225 & stationary \\
X5 & -1.528703 & -3.546099 & -2.91173 & -2.593551 & Not stationary \\
D(X5) & -6.683525 & -3.548208 & -2.912631 & -2.594027 & stationary \\
X6 & -1.487548 & -3.546099 & -2.91173 & -2.593551 & Not stationary \\
D(lnX6) & -6.680552 & -3.548208 & -2.912631 & -2.594027 & stationary \\
\hline
\end{tabular}

The ADF test results showed that the ADF statistics of LNY, $\ln X 1, \ln X 2, \mathrm{LnX} 3$, $\mathrm{X} 4, \mathrm{X} 5$, and $\mathrm{X} 6$ were greater than the critical values with the confidence of $1 \%, 5 \%$, and $10 \%$, indicating that $\mathrm{LNY}, \ln \mathrm{X} 1, \ln \mathrm{X} 2, \mathrm{LnX} 3, \mathrm{X} 4, \mathrm{X} 5$, and $\mathrm{X} 6$ are non-stationary sequences. Thus, the ADF test was conducted again for the first-order difference D (LNY), D (LnX1), D (LnX2), D (LnX3), D (X4), D (X5), and D (X6) of LNY, LnX1, 
LnX2, LnX3, X4, X5, and X6. The results showed that the first-order difference sequences of $\mathrm{LNY}, \mathrm{LnX} 1, \mathrm{LnX} 2, \mathrm{LnX} 3, \mathrm{X} 4, \mathrm{X} 5$, and $\mathrm{X} 6$ are stationary sequences, which meaned that they were first-order single integer sequences.

\subsection{Johansen cointegration test}

The Johansen cointegration test aims to determine whether the linear combination of a group of non-stationary sequences has a stable equilibrium relationship. The test results are shown in the table below:

Table 9: Johannsen's test under Linear deterministic trend

\begin{tabular}{|c|c|c|c|c|}
\hline $\begin{array}{l}\text { Hypothesized } \\
\text { No. of CE(s) }\end{array}$ & Eigenvalue & $\lambda_{\text {trace }}$ & $\begin{array}{l}\text { Critical Value at } \\
0.05\end{array}$ & P-value ** \\
\hline None* & 0.681063 & 136.3871 & 125.6154 & 0.0093 \\
\hline At most 1 & 0.574223 & 84.96279 & 95.75366 & 0.2188 \\
\hline At most 2 & 0.432940 & 46.53997 & 69.81889 & 0.7780 \\
\hline At most 3 & 0.192115 & 21.01189 & 47.85613 & 0.9844 \\
\hline At most 4 & 0.139075 & 11.41179 & 29.79707 & 0.9504 \\
\hline At most 5 & 0.070541 & 4.673110 & 15.49471 & 0.8425 \\
\hline At most 6 & 0.030228 & 1.381243 & 3.841466 & 0.2399 \\
\hline
\end{tabular}

Trace test indicates 1 cointegrating eqn(s) at the 0.05 level

* Denotes rejection of the hypothesis at the 0.05 level

**MacKinnon-Haug-Michelis (1999) p-values

Table 10 maximum eigenvalue test results

\begin{tabular}{ccccc}
\hline $\begin{array}{l}\text { Hypothesizedm } \\
\text { No. of CE(s) }\end{array}$ & Eigenvalue & $\lambda_{\text {trace }}$ & $\begin{array}{c}\text { Critical Value at } \\
0.05\end{array}$ & P-value.** \\
\hline None* & 0.681063 & 51.42427 & 46.23142 & 0.0128 \\
At most 1 & 0.574223 & 38.42282 & 40.07757 & 0.0759 \\
At most 2 & 0.432940 & 25.52808 & 33.87687 & 0.3502 \\
At most 3 & 0.192115 & 9.600106 & 27.58434 & 0.9898 \\
At most 4 & 0.139075 & 6.738675 & 21.13162 & 0.9635 \\
At most 5 & 0.070541 & 3.291868 & 14.26460 & 0.9254 \\
At most 6 & 0.030228 & 1.381243 & 3.841466 & 0.2399 \\
\hline
\end{tabular}

Max-eigenvalue test indicates 1 cointegrating eqn(s) at the 0.05 level

* Denotes rejection of the hypothesis at the 0.05 level

**MacKinnon-Haug-Michelis (1999) p-values

From the results of trace statistics and maximum eigenvalue in Johansen cointegration test of EViews, it can be seen that under the 5\% significance level, LnY, LnX1, LnX2, LnX3, X4, X5, and X6 did not have cointegration relationship, and the 
maximum eigenvalue and trace statistics are greater than the critical value of trace statistics, which could be considered as rejecting the original hypothesis. Based on table 9 and table 10, the results of the trace test and Max eigenvalue test show that there is a cointegration relationship, that is, there is a long-term equilibrium relationship between variables.

\section{Main conclusions}

This paper analysed the regional financial service function in the financial activities of enterprises and residents in Hunan Province, and concluded the following main conclusions:

4.1. There is a positive correlation between the loans of non-financial enterprises \& government organizations and the deposits of non-financial enterprises \& residents.

Deposits can be roughly divided into two parts: the deposits that commercial banks can lend, and the legal reserve deposit. The increasing in deposits between nonfinancial enterprises and residents would directly affect the total deposits of commercial banks, and thus cause the increasing in the loan amount of non-financial enterprises. After the regression analysis of non-financial deposits, resident loans and other independent variables on the loan amount of non-financial enterprises and government organizations, we concluded that there is a positive relationship between deposits and loans.

4.2. There is a positive correlation between resident loans and loans to nonfinancial enterprises and government organizations.

To a certain extent, residents leverage would enhance the crowding-out effect on consumption growth, instead of the income effect, which was not benefit for amplifying consumer consumption demand. However, in terms of enterprises, residents leverage will amplify consumers consumption ability, which can increase the proportion of enterprise financial investment and increase the loans of non-financial enterprises. At the meantime, debt risk also increases with the increase of loans and residents' leverage. 


\subsection{The decrease rate of loss-making enterprises, CPI, and 1-month SHIBOR}

interest rate have a negative correlation with the loan volume of non-financial enterprises and institutions.

The unit root test and cointegration test showed that with the increase of SHIBOR interest rate, the loan increase rate of non-financial enterprises would decrease. The reduction of enterprise loss rate, which takes the overall regional enterprises as the measurement object, could explain the development environment and development trend of the whole industry. High reduction rate of loss-making enterprises indicated that most enterprises in the region were profitable, and the development environment of enterprises is good.

\section{Countermeasures and Suggestions}

\subsection{Accelerate the process of regional financial integration in Hunan} Province and build a good ecological environment of regional financial market

A good financial market is mainly composed of a financial guarantee system, a credit system, and a supervision system. At present, many scholars point out that the inadequate guarantee system and credit system is one of the main reasons why small and micro enterprises face the financing problems. Therefore, it is urgent to build a new and efficient regional financial guarantee system and credit system, which should improve the credit guarantee system and supervision system. So as to effectively help the loan delivery of non-financial enterprises in Hunan Province, and to promote highquality development of the real economy in Hunan Province.

\subsection{Optimize loan structure and improve policy benefits}

According to the latest report, the national fixed asset investment (excluding farmers) increased by $25.6 \%$ from January to March 2021. From the analysis of the current situation of national macro-economy, China has continued to implement a prudent monetary policy in recent years, which has given certain support to the real economy and revitalized the market; From the microeconomic perspective, the main types of loans are concentrated in the industries and enterprises, so we should actively 
optimize the loan structure, to better promote the development of the real economy and maximize the benefits. On the other hand, in order to improve the problem of information asymmetry for small and micro enterprises, the government should enhance the publicity of preferential policies, set up special online and offline policy consultation. Therefore, those growing enterprises can be benefited from policy and developed better, finally improve the nation economy.

\subsection{Accelerate the construction of digital financial economy}

The 14th five-year plan points out that we should promote the construction of network power, accelerate the digital economy, digital society, and digital government, and drive the digital transformation in production mode, lifestyle, and governance mode. Building digital economy of regional finance is the first thing need to be done. With the development of Internet Finance and the introduction of corresponding laws and regulations, Internet online financing institutions other than banks will gradually mature. However, there is no effective and functional platform for enterprises to access relevant information and find a truthy finance institution, which affects the loan amount of non-financial enterprises to a certain extent. So, speeding up the construction of the financial digital economy is essential.

\subsection{Innovate the financial service system and inject new vitality into the regional financial service market}

Finance should serve the real economy. With Chinese government paying continuous attention to innovation, along with in technology and industry, the financial service system also needs revolution. From the regional financial service area, we can innovate the financial service mechanism according to different regional characteristics. Hunan Province is a large agricultural province, it is suitable to establish and improve the rural financial service system and develop green finance. From the service object of regional finance, the local government should promote the effective combination of finance \& agriculture, science \& technology, finance \& pension, so as to promote industrial transformation and upgrading. 


\section{Declaration}

Funding: Education Department of Hunan Province "Research on new agricultural development model under the combination of network traffic and tourism culture" (20C0580); Philosophy and Social Science Foundation of Hunan Province "Research on the coupling relationship between regional financial services and economic development in the construction of innovative Hunan" (XSP21YBC454)

Authors' contributions: First Author (Wen, Yi-xian): Data analysis, main conclusion

Corresponding Author (Liu, Zhi-ying): literature review, publishing, following modify

Competing interests: The authors declare no competing financial interests Acknowledgements: Not applicable

Ethics approval and consent to participate: The study received approval from two authors, Wen Yi-xian and Liu Zhi-ying, and the institutional review board of Hunan institute of Technology.

Consent for publication: The study received approval of publication from two authors, Wen Yi-xian and Liu Zhi-ying.

Availability of data and material: The datasets generated and/or analysed during the current study are available in The People's Bank of China (Changsha Central Sub-branch) repository, [http://changsha.pbc.gov.cn/changsha/130009/index.html]; and Hunan provincial Bureau of Statistics [http://tjj.hunan.gov.cn/hntj/tjsj/tjnj/index.html] 


\section{Reference}

Chen Bojun, An Analysis of Relationship between Credit Investment and Regional Economic Development under the Background of Economic Downturn: Taking Hengyang City as an Example[J]. Times Finance 2021(13): 61-64

Cheng Xue-zhen,Zhang Hai-an, An Study on the Difference and Explanation of Regional Credit Financing Capability in China-—From the Perspective of Economic Structure[J].Gansu Finance, 2017 (04) 37-41

Gao Bao-zhong, The Analysis on Influencing Factors of SME Loan Acquisition_—An Empirical Research Based on Survey Data of Henan Province. Financial theory \& practice,2014(08):3741

Liang Xiu-fen, Lin You-na,Research on Influence Factors of Credit Financing of Listed SMEs[J].Journal of Tongling University,2018,17(05):16-19.

Li Jun, Huang Qing-hua.An Empirical Study on the influencing factors of Small and Medium Sized Enterprises' financing in China [J].Special Zone Economy,2016(10):91-92.

LI Yu, ZHOU Huan, Empirical Analysis on the Impact of Regional Credit and Technological Innovation on Economic Growth: Based on the Spatial Panel Perspective[J].On Economic Problems, 2018(11):26-35

Zeng Jianhua. An Empirical Analysis of Regional Loan Growth: Case of Guangdong Province[J].South China Finance.2010, 401(01):18-20

Zhang Ge,Analysis the Loan Launch in Henan Province in Recent Years. Financial theory \& practice, 2010,(08):101-103

Zhao Zi-yi, Zhang Xin-yue,P2P Internet Lending Market and the Formal Financial Market-—An Empirical Analysis Based on the Spillover Effects [J].Review of Economy and Management,2018,34(04):108-118. 